\title{
Análisis de la producción científica en política y gestión educativa publicada en ScieLO 2012-2015
}

\section{Analysis of the Scientific Production in Politics and Educational Management Published in ScieLO 2012-2015}

\section{Análise da produção científica em política e gestão educacional publicada no SCIELO 2012-2015}

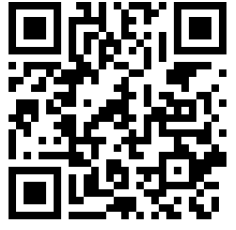

José González-Campos ${ }^{1}$

Universidad de Playa Ancha Valparaíso, Chile jgonzalez@upla.cl

(iD) https://orcid.org/000-0003-4610-6874

Juan Aspeé-Chacón ${ }^{2}$ Pontificia Universidad Católica de Valparaíso Valparaíso, Chile

juan.elias.aspee@gmail.com D http://orcid.org/0000-0003-3456-8414

Ida Sessarego-Espeleta ${ }^{3}$ Universidad de Playa Ancha Valparaíso, Chile

idasessarego@gmail.com https://orcid.org/0000-0001-7935-1775

Héctor González-Suárez ${ }^{4}$ Universidad de Playa Ancha Valparaíso, Chile

h.gonzalezsuarez@gmail.com iD https://orcid.org/0000-0003-2082-3779

Rosa Gómez-Osorio 5 Universidad de Playa Ancha Valparaíso, Chile rosyvalpo7@gmail.com

iD https://orcid.org/0000-0001-6892-0848

Recibido • Received • Recebido: 21 / 10 / 2016

Corregido • Revised • Revisado: 24 / 04 / 2018

Aceptado • Accepted • Aprovado: 14/ 06 / 2018

\footnotetext{
${ }^{1}$ Doctor en Estadística. Coordinador del laboratorio investigación e experimentación de saberes matemáticos e integrante del claustro académico del Doctorado en Políticas y Gestión Educativa de la Universidad de Playa Ancha, Chile.

2 Docente agregado en Pontificia Universidad Católica de Valparaíso. Doctor en Políticas y Gestión Educativa de la Universidad de Playa Ancha, Chile.

${ }^{3}$ Doctoranda en Políticas y Gestión Educativa de la Universidad de Playa Ancha, Chile.

${ }^{4}$ Doctorando en Políticas y Gestión Educativa de la Universidad de Playa Ancha, Chile.

${ }^{5}$ Doctoranda en Políticas y Gestión Educativa de la Universidad de Playa Ancha, Chile.
} 
doi: http://dx.doi.org/10.15359/ree.22-3.7

URL: http://www.una.ac.cr/educare

CORREO: educare@una.cr

Resumen: La cienciometría, como medición de la producción científica, impulsa las investigaciones en educación a nuevos estándares de rigurosidad, conexión e interacción entre investigadores e investigadoras. La misma cienciometría sirve como medición y, al mismo tiempo, como guía para atender las temáticas en boga o detectar a aquellas postergadas. En tal sentido, el presente trabajo se propone analizar y formular un índice de productividad científica en temáticas de políticas y gestión educativa en publicaciones SCIELO entre los años 2012-2015. Así, se resumen y organizan las frecuencias de la producción científica publicada en temáticas de política y gestión educativa, y se presenta un índice organizar dicha producción para cada uno de los 15 países constituyentes de la base de indexación SCIELO. Este índice permitió identificar los países con menor riesgo y estables longitudinalmente en relación con la producción científica en esta temática: Bolivia, Brasil y Uruguay. Asimismo, identificó los países de mayor riesgo e inestabilidad en la misma área: Perú y África del Sur. Esto justifica la necesidad de establecer estándares relativos a la producción científica en políticas y gestión educativa. Asimismo, se abre una línea de investigación en torno a la cienciometría en esta misma, junto con establecer criterios para la toma de decisiones.

Palabras claves: Homogeneidad; cienciometría; educación; índice.

Abstract: Scientometrics, as a measurement of scientific production, connects researches together and drives education research to new rigorous standards. Scientometrics can be used as a measurement as well as a guide to address current and neglected issues. In this regard, the primary purpose of this paper is to analyze and elaborate education policy and management issues utilizing the scientific research in the SCIELO publications between 2012-2015 of 15 countries. Education policy and management issues are organized and summarized in a scientific frequency index. This index allows identifying countries with the lowest risk and highest stability such as; Bolivia, Brazil, and Uruguay. Equally, the index identifies countries with the highest risk and lowest stability such as; Peru and South Africa. This warrants the need to establish education policy and management standards employing scientific measurement. Equally, it opens the need for scientometrics research and establishing criteria for the decision making process.

Keywords: Homogeneity; scientometrics; education; index.

Resumo: A cienciometria, como medida da produção científica, leva a pesquisa em educação a novos padrões de rigor, conexão e interação entre pesquisadores. A própria cienciometria serve como uma medida e, ao mesmo tempo, guia para atender as temáticas em voga ou detectar aquelas postergadas. Nesse sentido, o presente trabalho pretende analisar e formular um índice de produtividade científica em questões políticas e gestão educacional nas publicações do SCIELO entre os anos de 2012-2015. Assim, as frequências da produção científica publicadas em temas de política educacional e gestão são resumidas e organizadas, e é apresentado um índice para organizar essa produção para cada um dos 15 países constituintes da base de indexação SCIELO. Esse índice permitiu identificar os países com menor risco e longitudinalmente estáveis em relação com a produção científica nesta matéria: Bolívia, Brasil e Uruguai. Da mesma forma, identificou os países de maior risco e instabilidade na mesma área: Peru e África do Sul. Isso justifica a necessidade de estabelecer padrões relacionados com a produção científica em políticas e gestão da educação. Da mesma forma, abre-se uma linha de pesquisa em torno da cienciometria na mesma, juntamente com o estabelecimento de critérios para a tomada de decisão.

Palavras-chave: Homogeneidade; Cienciometria; educação; índice. 


\section{Introducción}

El análisis de la producción científica en temas educativos se ha convertido en el último tiempo en un factor constitutivo y constituyente de la misma área de preocupación científica. Es así como la didáctica, los modelos de enseñanza, los enfoques de aprendizaje, los currículos, las políticas y la gestión educativa, etc., se acompañan por el análisis y escudriñamiento de los vínculos de producción del conocimiento. En este sentido, el análisis cuantitativo de la producción científica se conoce como cienciometría, consistente en la medición de los productos publicados del conocimiento científico: se describen tendencias, se generan índices y relaciones entre temáticas, entre un sin fin de usos (Cruz-Ramírez, Escalona-Reyes, CabreraGarcía y Martínez-Cepena, 2014).

En dicho contexto, se relevan entrelazamientos de citas, fertilidad de autores y autoras, recurrencia y profundidad de temas abordados, entre otros factores, convirtiendo el uso de la cienciometría en una necesidad para el avance científico de la investigación en educación (Diem y Wolter, 2013). Así, y como ejemplo, utilizan la cienciometría Cardona-Román y Sánchez-Torres (2017) para analizar las tendencias acerca de la educación e-learning, o Corrales-Reyes, FornarisCedeño y Reyes-Pérez (2017) para escudriñar la investigación publicada sobre educación médica. No obstante, este proceso no está exento de controversias, ya que la excesiva cuantificación tiene el riesgo de relegar aquellos factores más cualitativos del impacto y contexto de la producción científica. Curiosamente, la solución a lo anterior está justamente en la adecuada ponderación de las variables cualitativas, especialmente de las dimensiones de contexto en el que se desarrollan y socializan las mismas investigaciones (Arencibia y De Moya, 2008; López, 2017). En tal sentido, la correcta construcción de índices complejos y adecuadamente ponderados permite a la cienciometría sintetizar las variables cuantitativas y cualitativas más relevantes de la producción científica, de manera que se desarrolla aún más (López, 2017). En tal sentido, la cienciometría constituye una endo-investigación, o investigación de segundo orden que facilita considerablemente los metaanálisis.

Un ejemplo destacable de estudio cienciométrico en temáticas educativas en general es el de Fernández y Bueno (1998), quienes, al considerar 29 estudios españoles, concluyeron que existe un predomino de estudios de tipo descriptivos; que el $90 \%$ de los trabajos son individuales; que el área de mayor exposición y recurrencia es la didáctica; y que las citas acumuladas son escasas, pese a la relativa gran producción. También la investigación de Cabrera (2016) llevó a cabo una revisión de la producción científica española en educación entre los años 1980 y 2011, centrada en la temática del rendimiento académico, sentencia que existe un gran número de autores y autoras, pero con baja producción y heterogeneidad de lugares donde publican; que las temáticas más recurrentes refieren a modelos explicativos, diagnósticos y tratamiento del rendimiento académico, factores y variables determinantes, y estudios sobre legislación y de otras variables psicológicas y educativas. De la misma forma, Ortiz (2015) realizó una evaluación del impacto científico en las investigaciones 
doi: http://dx.doi.org/10.15359/ree.22-3.7

URL: http://www.una.ac.cr/educare

CORREO: educare@una.cr

educativas realizadas por integrantes del Centro de Estudios sobre Ciencias de la Educación Superior de la Universidad de Holguín, Cuba, entre los años 2002-2012. En dicho periodo se publicaron 16 libros y se concibieron 49 artículos que fueron publicados principalmente por revistas cubanas $(71,4 \%)$, cuya mayor producción se generó el año 2009. Estos artículos recibieron 177 citas, la mayor parte de las cuales las concentra solo un investigador (63,2\%). Sin embargo, este estudio no hace referencia a las principales temáticas tratadas en dichas publicaciones.

Considerando lo anterior, en particular este trabajo pretende analizar y formular un índice de productividad científica en política y gestión educativa para cada país constituyente de la base de indexación SCIELO, que capture, de manera integral, aspectos como admisibilidad, cobertura y estabilidad longitudinal de dicha producción entre los años 2012 al 2015, ambos años inclusive. La centralidad de la temática de políticas y gestión educativa radica en que son materias altamente sensibles para el desarrollo de los sistemas educacionales de cualquier país y en cualquier nivel. La gestión educativa es una disciplina relativamente nueva con bajo nivel de especificidad y estructuración, que busca aplicar los principios generales de la gestión al campo específico de la educación (Casassus, 2002), y que impacta todos los aspectos cotidianos de los sistemas educacionales, así lo ejemplifica Rico (2016) para el caso de la formación docente. Mientras que la política educativa, como expresión de la voluntad gubernamental respecto de lo que se desea alcanzar en los sistemas educacionales y con estos, enmarca dicha gestión, generando efectos discursos y performativos de alto impacto social (Acuña, Assaél, Contreras y Peralta, 2014; Ball, 2014; Bourdieu, 1997).

Enfocado, entonces, en la producción de conocimiento en políticas y gestión educativa, es pertinente señalar que su desarrollo es exiguo, con muy pocas investigaciones latinoamericanas, con fuerte concentración en España. Asimismo, son escasos los estudios longitudinales en la materia. Es en esta nueva esfera de conocimiento desde donde se construye la presente propuesta, cuyo objeto de atención, la producción académica de artículos centrados en políticas y gestión educativa, trata de ser condensada en medidas cuantificables que guíen el camino del público lector e investigador interesado en dicha área. Aunque se debe considerar que la preocupación respecto del producción científica en la temática en cuestión no es nueva, y que el presente escrito viene a contribuir al desarrollo de un camino ya trazado con trabajos como el de Fernández, Torralbo, Rico, Gutiérrez y Maz (2003), quienes efectuaron una exploración cienciométrica de la productividad y citación en 135 tesis doctorales españolas desde 1976 a 1998, donde señalaron que el $14,8 \%$ de las citas analizadas refieren a temas de política educativa y sistema educativo.

Por otro lado, Osorio (2007) efectuó una revisión sobre la investigación educativa en México, centrado en la producción de la Revista Mexicana de Investigación Educativa (RMIE) desde 1996 a junio de 2004 . Señala que el $18.5 \%$ del total de publicaciones en dicho periodo de tiempo se relacionaba con temáticas de política y educación. Hecho que reafirmó los hallazgos de Rizo (2000, en Osorio, 2007), quien encontró que este tema ocupaba el 22\% de los artículos 
publicados hasta 1999. Por su parte, el 9,73\% de los artículos analizados referían a temáticas de gestión y organización de instituciones de educación, lo que, sumado al anterior hallazgo, arrojó que el $28,23 \%$ de los artículos refirió a temáticas de política y gestión en el ámbito educativo.

En Chile, es destacable el trabajo de Villalobos, Band, Torres y González (2016), quienes realizaron un estudio de caracterización de las investigaciones acerca de política educativa realizadas en el país entre 2000 y 2011 . Mediante un análisis de contenido en 173 investigaciones en políticas educativas, establecieron que existen diferencias sustanciales en los objetos, objetivos de investigación y aproximaciones teóricas entre las investigaciones desarrolladas desde la lógica estatal y las investigaciones desarrolladas con la lógica académica. Asimismo, establecieron que la temática más recurrente en estas investigaciones fue la calidad educativa y el uso de herramientas de gestión, mayoritariamente con una metodología mixta (cualitativa y cuantitativa).

De esta manera, y mediante una revisión de la base de indexación SCIELO, el presente trabajo pretende aportar a la discusión anterior con el ofrecimiento de una revisión cienciométrica ampliada que propone un índice omnímodo $\left(I_{\circ}\right)$ que jerarquiza a los 15 países representados en esta base, en función de la producción científica del área de políticas y gestión educativa (PYGEDU). Para llegar a tal índice ( $\left.\mathrm{I}_{\mathrm{o}}\right)$, se hizo necesario, primero, realizar un recorrido descriptivo de frecuencias absolutas y relativas, así como el análisis a través de medidas de posición y medidas de variabilidad. Este índice $\left(\mathrm{I}_{\mathrm{o}}\right)$ viene a llenar una carencia de criterios cienciométricos integrales relativos a la producción científica en políticas y gestión educativa.

\section{Metodología}

\section{Tipo de estudio, enfoque y diseño}

Esta investigación es de carácter propositiva, descriptiva y longitudinal, pues presenta un índice que resume características cienciométricas de los países con revistas en la base de indexación SCIELO en temáticas de políticas y gestión educativa (PYGEDU); resume y organiza las frecuencias productivas de artículos, y considera como cohorte los años 2012, 2013, 2014 y 2015.

\section{Especificación de la muestra}

La base de indexación SCIELO está constituida por 15 países: África del Sur, Argentina, Bolivia, Brasil, Chile, Colombia, Costa Rica, Cuba, España, México, Paraguay, Perú, Portugal, Uruguay y Venezuela. Se eligió esta base de indexación, pues es una plataforma de acceso gratuita que agrupa una gran parte de los países hispanohablantes y con un desarrollo económico similar a Chile, país de origen del grupo investigador y que se tratará como referente en la exposición de los resultados. 
doi: http://dx.doi.org/10.15359/ree.22-3.7

URL: http://www.una.ac.cr/educare

CORREO: educare@una.cr

En dicha base, se identificaron 76 revistas caracterizadas por admisibilidad en los temas relacionados con educación en los períodos 2012-2015. De estas 76 revistas se seleccionaron intencionalmente (no probabilístico) 2.049 artículos relacionados a la temática de PYGEDU, desde un total de 8.948 artículos, se tuvo una cobertura de casi un $25 \%$. Se entendió que un artículo se relacionaba con este tema cuando trataba asuntos relativos a:

a) Política educativa: que refiere a las consideraciones del manejo de lo político, por medio de la política en la educación, donde lo político se liga a las dimensiones de antagonismo, que se organiza por medio de la política (Díaz, 2003; Mouffe, 1999). Es decir, las temáticas de política educativa son todos aquellos aspectos que discutan sobre la organización, estructura, participantes, valores y fines de la educación.

b) Gestión educativa: que refiere a los artículos que analicen, estudien o discutan acerca de las acciones de manejo y cometido de los sistemas escolares y sus instituciones en particular; y en general que analicen los principios de la gestión aplicados a la educación (Casassus, 2002).

Estas temáticas se detectaron mediante la revisión de la redacción de los resúmenes de los artículos y las palabras claves que dichos artículos contenían (educación; gestión educacional; sistemas educativos; calidad en -o de- la educación; política educativa; entre otras). Considerando las definiciones precedentes, y mediante la participación de este equipo de 5 personas investigadoras se determinó por cada uno de los 8.948 artículos la pertinencia a la temática de políticas y gestión educativa.

\section{Objeto y objetivo de estudio}

El objeto de estudio está constituido por las frecuencias de producción de artículos con temáticas de políticas y gestión educativa.

El objetivo de investigación es: Formular un índice de productividad científica en política y gestión educativa para cada país constituyente de la base de indexación SCIELO, que capture, de manera integral, aspectos como admisibilidad, cobertura y estabilidad longitudinal, en la cohorte de los años 2012-2015.

\section{Planteamiento del problema e hipótesis}

Carencia de criterios cienciométricos integrales relativos a la producción científica en PYGEDU respecto de los 15 países constituyentes de la base de indexación SCIELO.

Se indica que el estudio no es inferencial, ni de contraste. No obstante, se hará el planteamiento de una hipótesis descriptiva con el fin de guiar la investigación. 
Hipótesis: La producción científica en PYGEDU, según el índice omnímodo, en los 15 países de la base de indexación SCIELO es homogénea y estable en el tiempo en términos relativos.

\section{Forma funcional de los índices utilizados}

a) Índice de admisibilidad: $I_{A}=\frac{\text { TAEPP }}{\text { TAPP }} 100 \%$, donde TAEPP representa el total de artículos de educación por país, TAPP el total de artículos por país de manera general.

b) Índice de cobertura: $l_{c}=\frac{\text { TAPGUPP }}{\text { TAEAPP }} 100 \%$, donde TAPGUPP representa el total de artículos de política y gestión por país, TAEAPP el total de artículos en revistas con admisibilidad en educación por país.

c) Índice de heterogeneidad: coeficiente de variación de la variable en cuestión.

d) Índice omnímodo: $I_{o}=\frac{\left(I_{A}+I_{c}+I R+I P C E\right) 100}{4} \%$, donde IR representa el incremento relativo, IPCE el porcentaje de revistas de admisibilidad de educación respecto del total de revistas del país.

\section{Resultados}

\section{Índice de admisibilidad de artículos de educación en revistas SCIELO (I $)$}

Este índice cuantifica el porcentaje de artículos relacionados con las temáticas educativas presentes en el total de revistas que se generan en cada país. Así, mientras más próximo I esté de 100, se tendrá mayor evidencia de admisibilidad a revistas de educación. Asimismo, cuantifica el impacto porcentual de la temática educación en cada país que integra la base de indexación SCIELO.

En la Figura 1 se ha representado de manera cuadriculada el valor medio para $\mathrm{I}_{\mathrm{A}^{\prime}}$ que alcanza el 9\%, evidenciando la importancia que es depositada sobre las temáticas educativas. Se insiste en que la temática educación caracteriza casi un décimo del total de las líneas de investigación a nivel global, es por ello que se establece que existe una alta admisibilidad. Este índice permite hacer comparaciones en una misma escala, debido a la existencia de países como Brasil o México, cuyas frecuencias absolutas son superiores a los demás países.

Para el caso específico de Chile, el I está bajo la media en 4\%, esto significa que del total de revistas que se producen en Chile, solo el $5 \%$ de ellas admiten artículos que contienen temáticas educativas. 
doi: http://dx.doi.org/10.15359/ree.22-3.7

URL: http://www.una.ac.cr/educare

CORREO: educare@una.cr

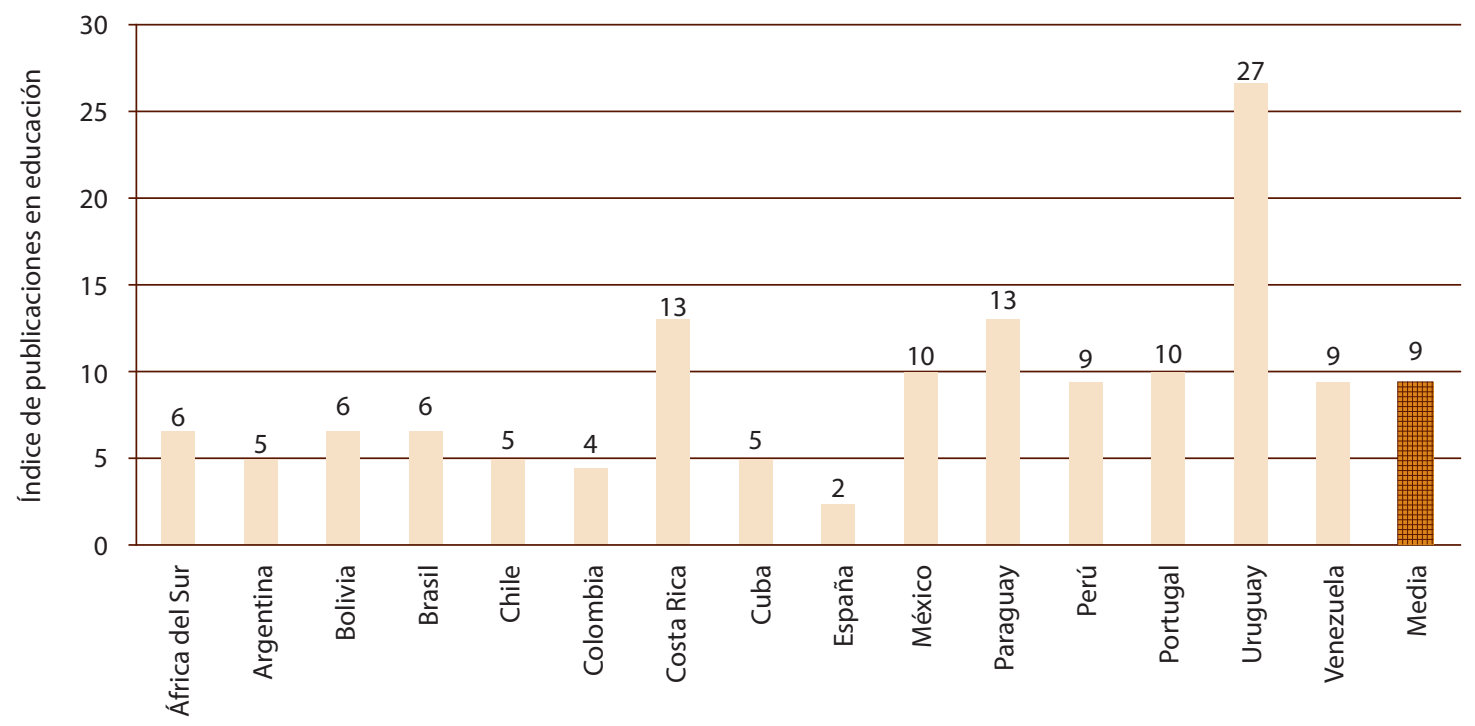

Países en base de indexación SciELO

Figura 1: Dinámica de I en SCIELO (2012-2015).

Nota: Elaboración propia.

\section{Contraste en términos absolutos de la producción científica en PYGEDU}

En la Figura 2 se hace evidente la superioridad cuantitativa de Brasil y México en términos absolutos, sobrepasando la producción media de artículos PYGEDU en 237 unidades respecto de España y Paraguay. Sin embargo, es una comparación injusta, ya que no se considera los tamaños poblacionales ni su índice de admisibilidad. Pese a ello, Chile se encuentra por la media, posicionándose en el tercer país con mayor productividad PYGEDU, adquiriendo mayor relevancia, pues su tamaño poblacional dista significativamente de gran parte de los que constituyen la base de indexación SCIELO.

La Figura 3 presenta un resumen de la heterogeneidad longitudinal, con el fin de dar consistencia a las medidas de resumen indicadas en la Figura 2.

La Figura 3 resta impacto a la producción científica de PYGEDU de países como Brasil y México, que poseen las frecuencias absolutas más altas. Estos países, en términos de heterogeneidad, presentan los puntajes más altos; se refleja, con esto, la no existencia de estándares de admisibilidad preestablecidos para artículos PYGEDU y se evidencia una inestabilidad temporal en la cantidad de este tipo de artículos entre los años 2012 a 2015 . En cambio, Venezuela, pese a presentar una media en producción PYGEDU baja, es estable en dicho tiempo. En el caso de Chile, se visualiza en la Figura 3, que se encuentra sobre la media en cuanto a heterogeneidad, lo que significa que existen desafíos en cuanto a establecer políticas de estandarización y homogeneización de la cantidad de artículos destinados a PYGEDU. 
doi: http://dx.doi.org/10.15359/ree.22-3.7

URL: http://www.una.ac.cr/educare

CORREO: educare@una.cr

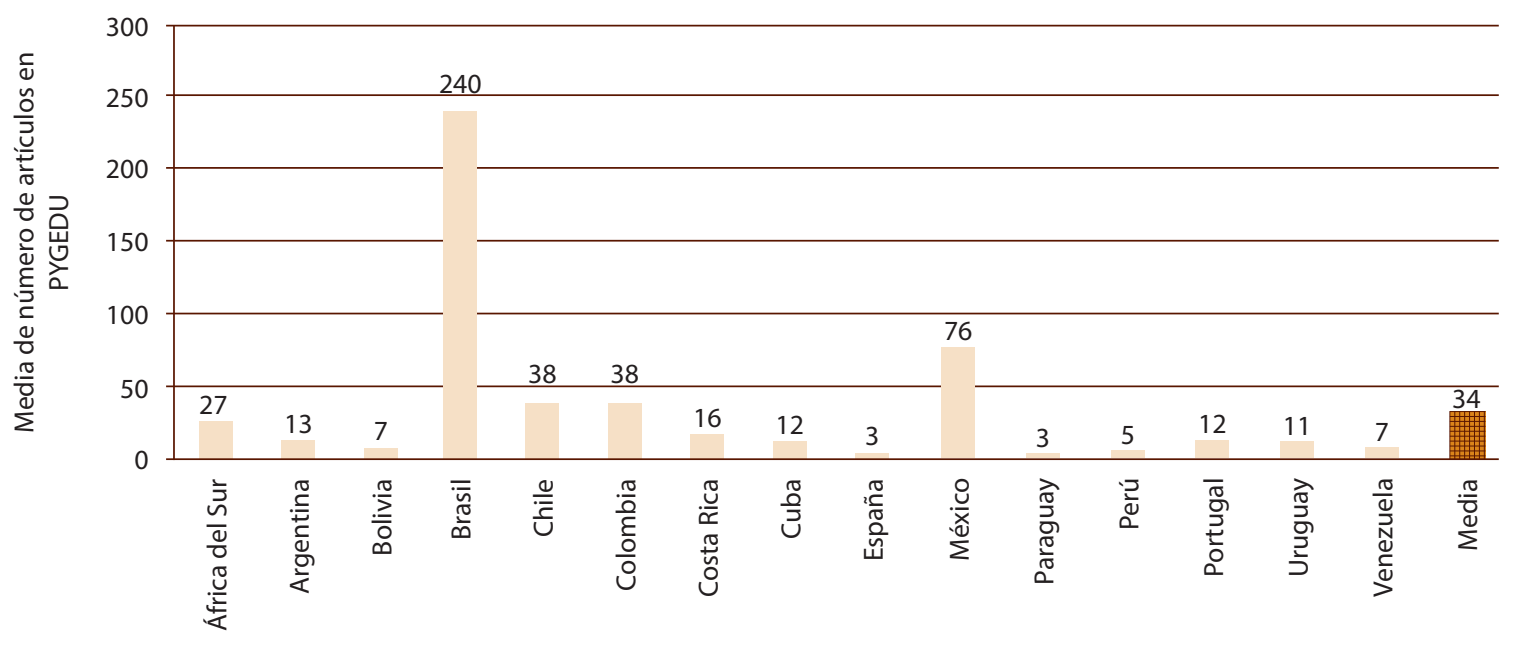

Países en base de indexación SciELO

Figura 2.: Frecuencias absolutas de la producción científica PYGEDU (2012-2015).

Nota: Elaboración propia.

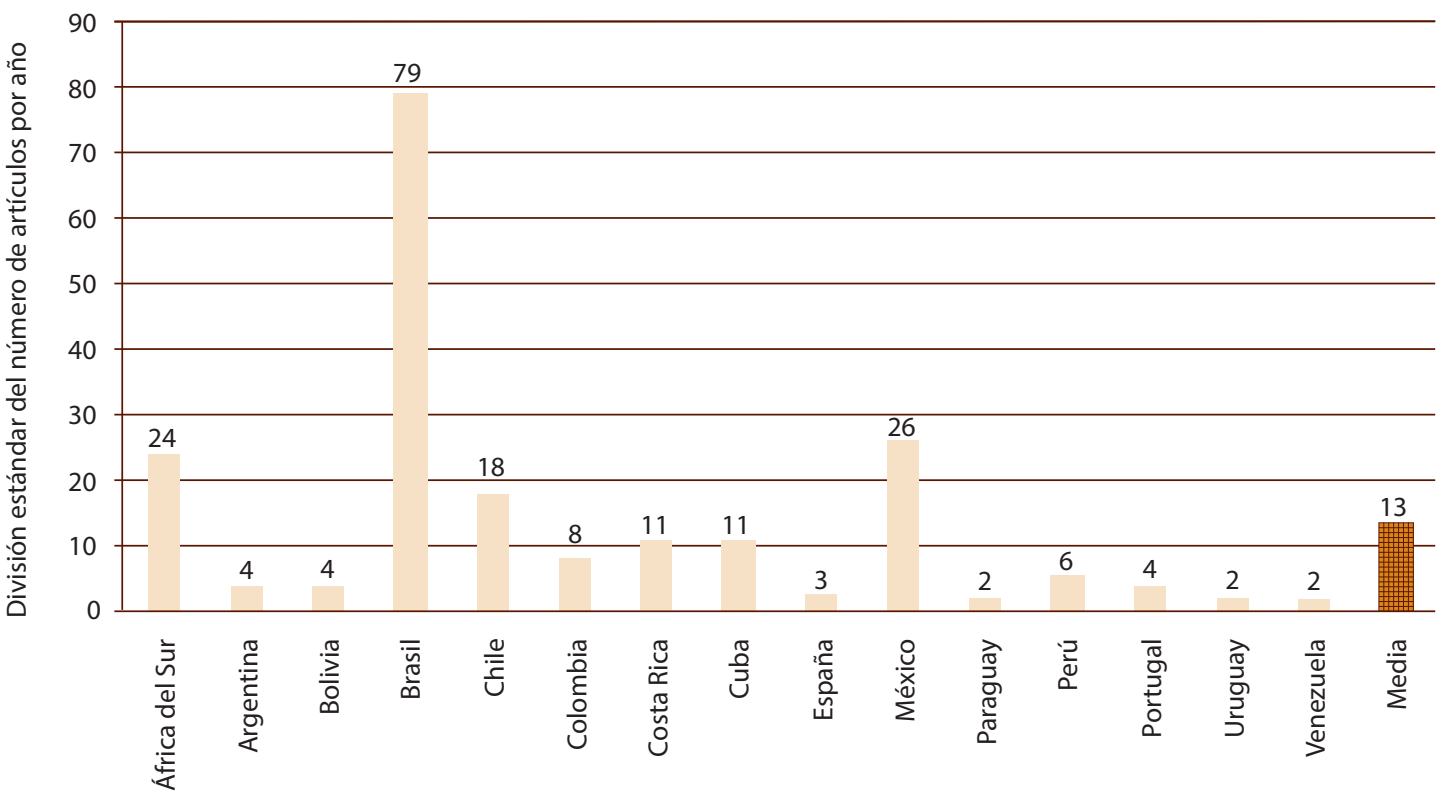

Países en base de indexación SciELO

Figura 3: Contraste de la media de producción científica en PYGEDU (2012-2015).

Nota: Elaboración propia. 
doi: http://dx.doi.org/10.15359/ree.22-3.7

URL: http://www.una.ac.cr/educare

CORREO: educare@una.cr

La Figura 4 presenta un resumen longitudinal de los países cuyas medias en artículos PYGEDU caracterizan situaciones extremas, permitiendo visualizar el efecto temporal del índice de homogeneidad descrito en la Figura 3.

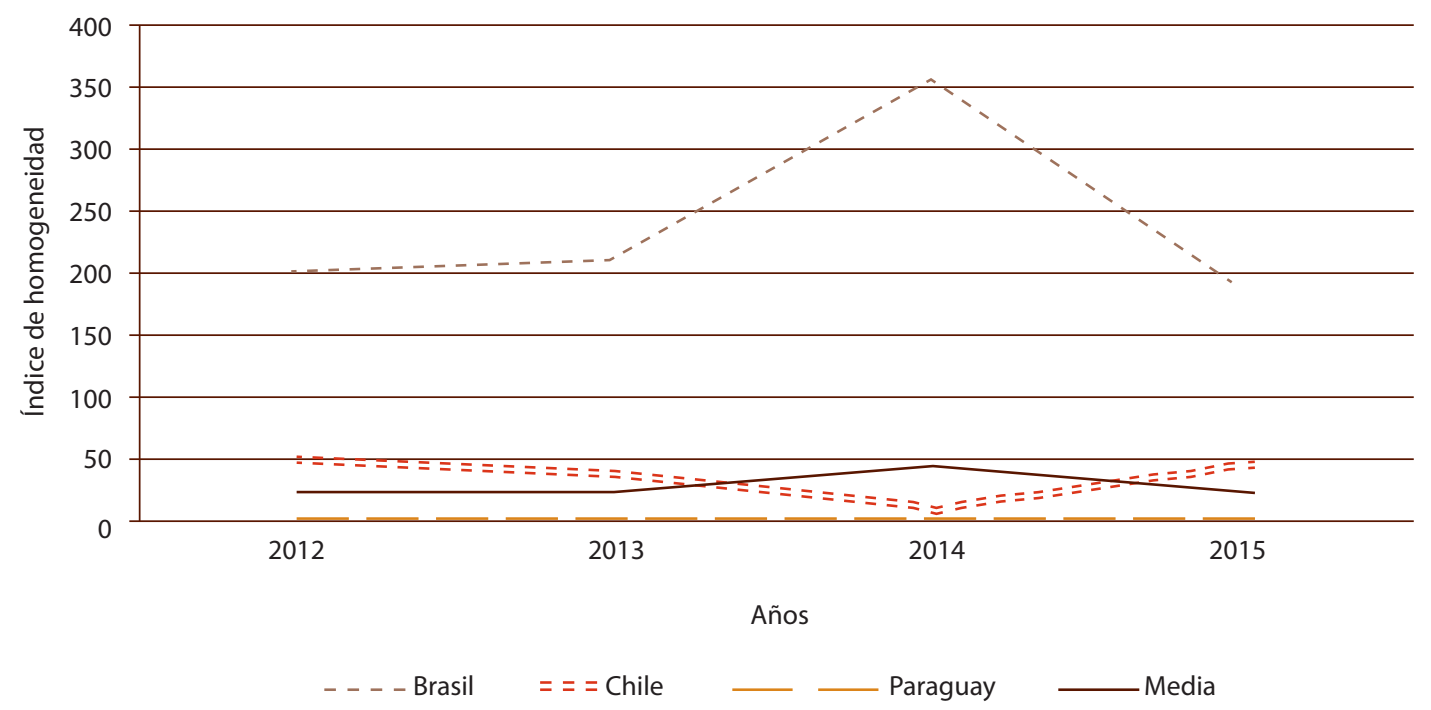

Figura 4: Representación de las frecuencias de artículos PYGEDU (2012-2015). Nota: Elaboración propia.

En la Figura 4 se visualizan las dinámicas longitudinales de Brasil y Paraguay como situaciones extremas. Brasil alcanzó la mayor media en artículos PYGEDU en los 4 años en estudio y Paraguay la menor. Se evidencia que la superioridad de Brasil es constante al paso de los 4 años de estudio, visualizándose un incremento en el año 2014, aspecto consistente al alto índice de heterogeneidad descrito en la Figura 3. También se observa un incremento importante en la producción PYGEDU de Brasil de 2012 a 2014. Sin embargo, dicha tendencia se detiene en el 2015, lo que nuevamente refleja la inexistencia de una política clara respecto a la producción científica en PYGEDU. Para el caso de Paraguay, se observa homogeneidad y baja producción científica de artículos PYGEDU, no se visualiza ninguna tendencia. Por su parte, Chile presenta una disminución importante en su producción PYGEDU en el año 2014. Este aspecto abre una línea interesante de investigación, en función de entender este comportamiento atípico de Chile en dicho año. 


\section{Índice de cobertura media de artículos PYGEDU en revistas con admisibilidad de temáticas de educación $\left(I_{c}\right)$}

Este índice especifica el porcentaje de artículos PYGEDU que son admisibles en revistas cuyos artículos presentan temáticas educacionales. I es un valor porcentual, en donde 100 representa la totalidad de las revistas de admisibilidad educativa que tratan problemáticas PYGEDU. La Figura 5 presenta un resumen de $I_{C}$ en la base de indexación SCIELO.

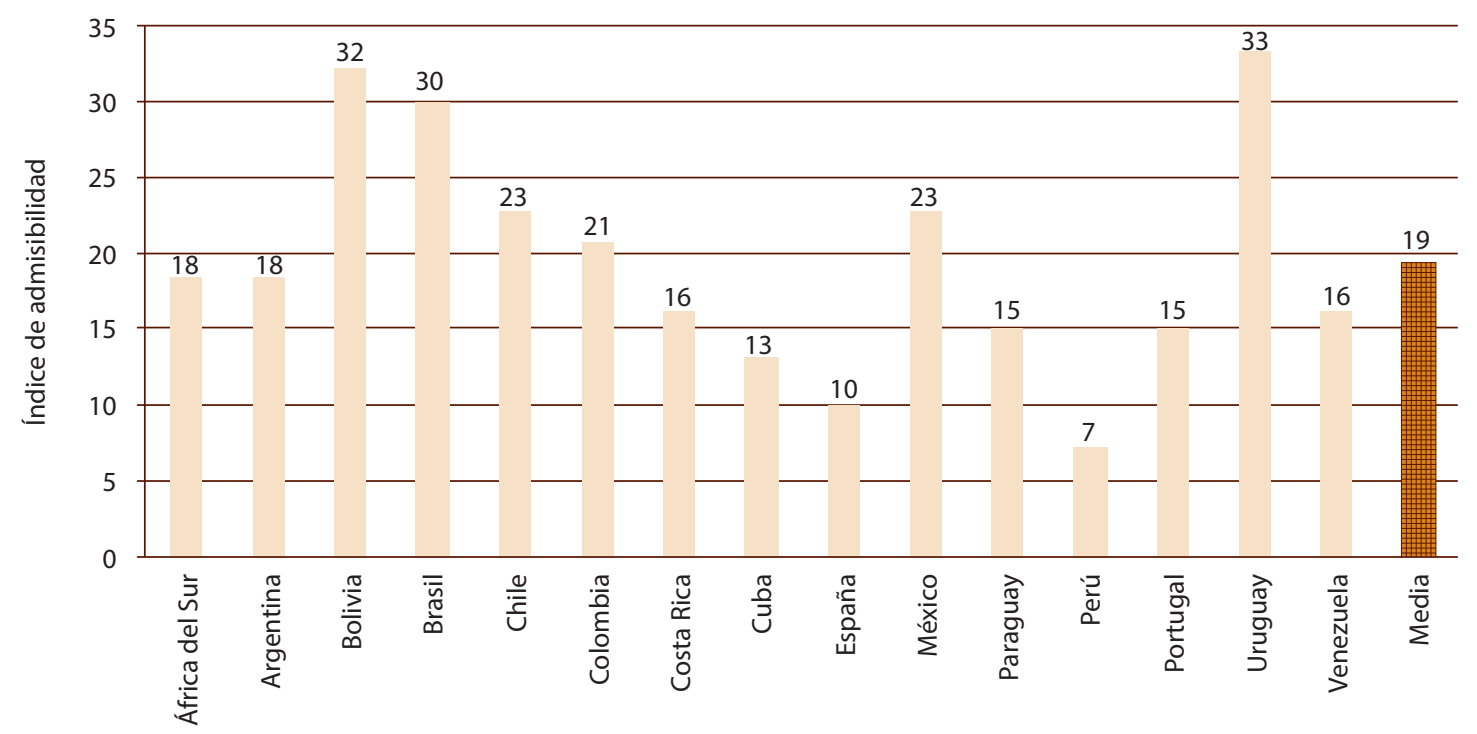

Países en base de indexación SciELO

Figura 5: Índice de cobertura en PYGEDU (2012-2015).

Nota: Elaboración propia.

Se observa en la Figura 5 que Uruguay presenta el mayor $I_{C^{\prime}}$ alcanzando un 33\%, esto significa que, de todas las revistas de admisibilidad de artículos en educación, el 33\% de ellas asumen el compromiso con PYGEDU. Asimismo, la media, representada por la barra cuadriculada en la Figura 5 es de 19\%. Este porcentaje resulta importante al considerar la variada gama de líneas de investigación que constituyen la educación (didáctica, aprendizaje, currículo, etc.). Para el caso de Chile el $\mathrm{I}_{\mathrm{c}}$ es de $23 \%$, sobre la media, y refleja un notorio compromiso de la educación con PYGEDU, se sitúa en el cuarto lugar de cobertura.

El $\mathrm{I}_{\mathrm{C}}$ es complementado y adquiere representatividad en la Figura 6, que resume la variabilidad longitudinal de la cobertura, permitiendo caracterizar países que según su media presentan una alta cobertura, pero también alta variabilidad, lo que hace suponer que no existe un estándar claro de línea editorial en PYGEDU. 
doi: http://dx.doi.org/10.15359/ree.22-3.7

URL: http://www.una.ac.cr/educare

CORREO: educare@una.cr

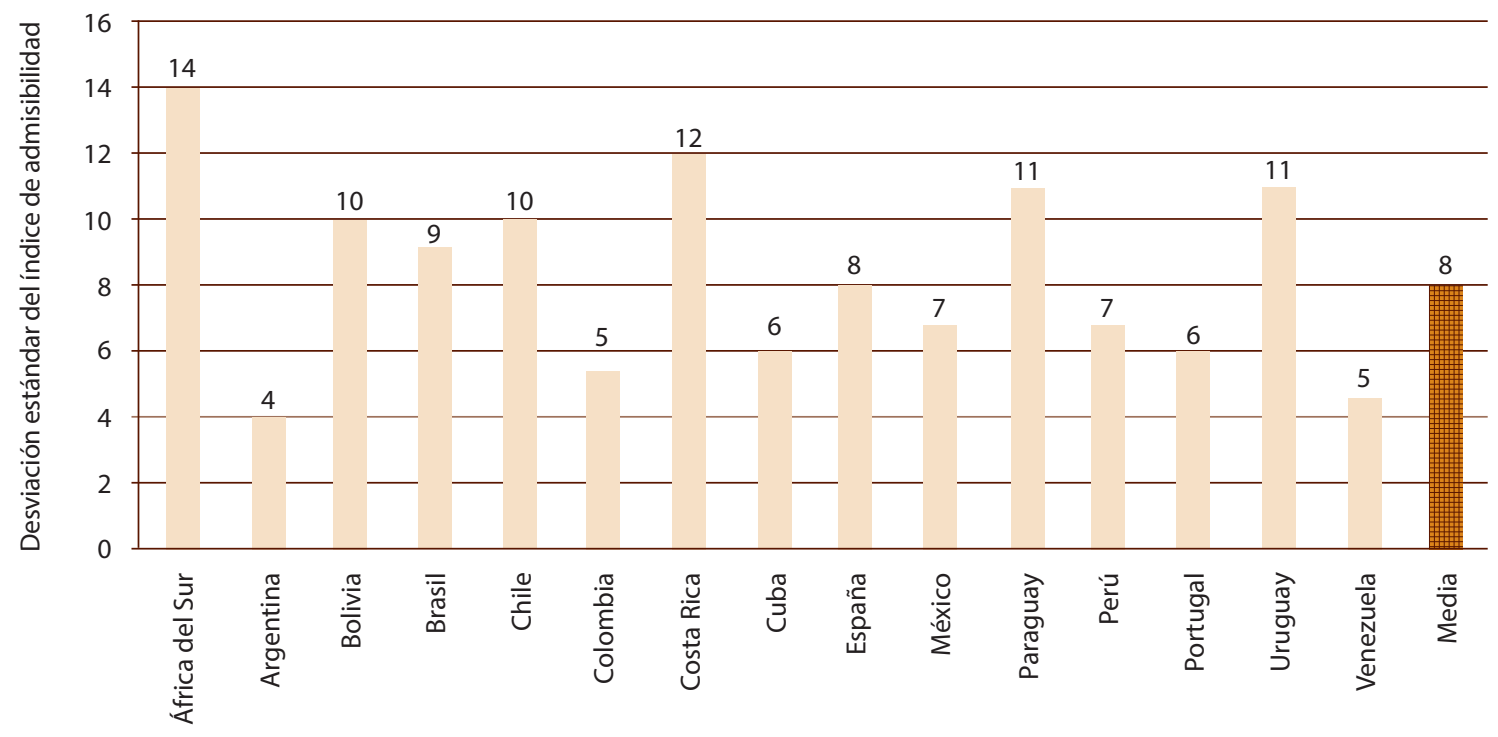

Países en base de indexación SciELO

Figura 6: Estabilidad de la cobertura media de artículos publicados en PYGEDU (2012-2015).

Nota: Elaboración propia.

El desafío que proyecta la Figura 6 se traduce en disminuir la heterogeneidad del $I_{C^{\prime}}$ caracterizada por una media de $8 \%$ (ver barra cuadriculada en Figura 6), que homogenice la cobertura media de cada país. Es importante resaltar a Argentina, que está levemente bajo la media en el $I_{c^{\prime}}$ no obstante, es el país que presenta menor heterogeneidad productiva en PYGEDU. Ello haría suponer un eventual incremento del riesgo de rechazo de un artículo ante un aumento de artículos PYGEDU, que deseen ser publicados en revistas de dicho país.

\section{Índice de heterogeneidad longitudinal de artículos publicados de PYGEDU en revistas con admisibilidad de artículos en temáticas de educación}

Este índice resume la variabilidad longitudinal de la producción PYGEDU (ver Figura 7, línea PG), el que contrasta la variabilidad total del número de artículos de las revistas con admisibilidad de educación, respecto de la variabilidad del número de artículo PYGEDU en estas mismas revistas. Se observa que Perú presenta el mayor índice de heterogeneidad en PYGEDU y uno de los más bajos en términos de totales (ver Figura 7, línea N), situación que se traduce en estabilidad en la cantidad de artículos de educación. Con todo, si se observan solo los artículos PYGEDU, estos presentan un comportamiento totalmente heterogéneo. Asimismo, 
es importante resaltar a Uruguay, cuya producción en PYGEDU es estable, lo que puede inferir la existencia de una política de proporcionalidad para artículos en dicha área, en sus revistas con admisibilidad de temáticas de educación. Por lo tanto, en un contraste entre Perú y Uruguay, ante un aumento en la generación de artículos PYGEDU se supone conveniente someter artículos en revistas de Perú. Este índice puede ser asociado con el concepto de flexibilidad en la situación de incremento de conocimiento científico.

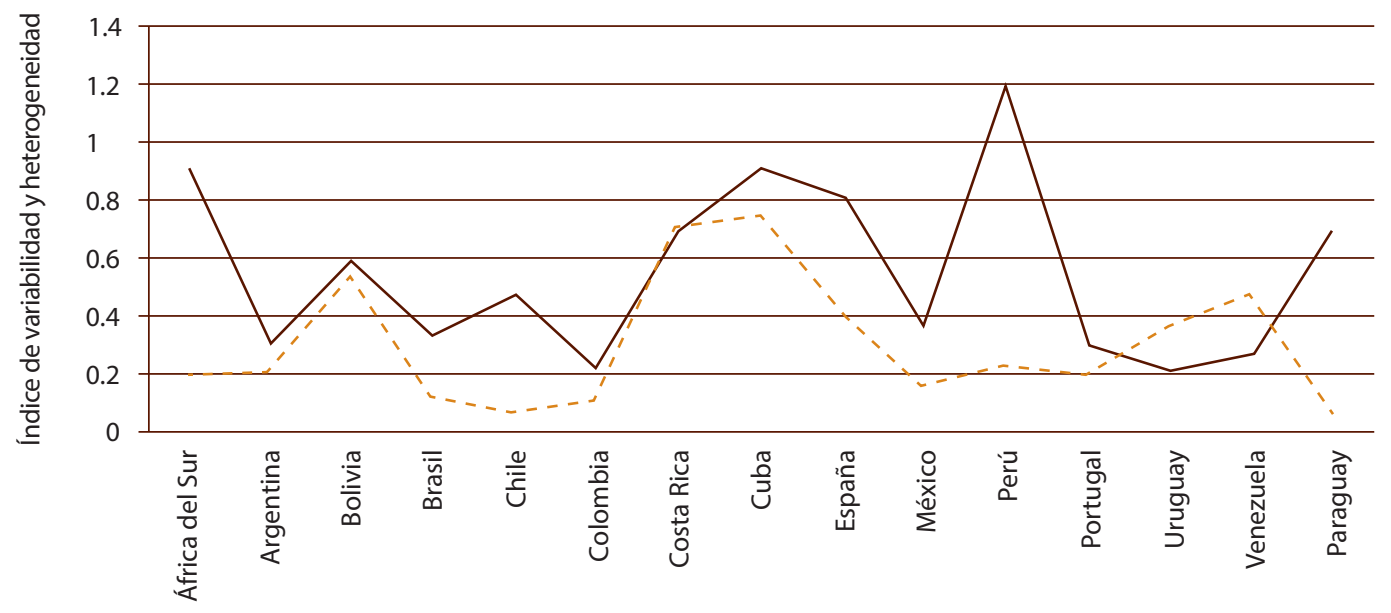

Países en base de indexación SciELO

$\longrightarrow P G \quad----N$

Figura 7: Heterogeneidad para la producción PYGEDU (2012-2015). Nota: Elaboración propia.

\section{Î́ndice omnímodo del número de artículos PYGEDU $\left(\mathrm{I}_{\mathrm{o}}\right)$}

Este índice propone un criterio objetivo de decisión a la hora de escoger el país al cual se pretende someter un artículo PYGEDU. El I es un valor porcentual, donde 100 representa que el país en cuestión tiene la mayor cantidad de características métricas positivas a la admisibilidad del artículo. Por ende, I o permite tener una cuantificación integral en torno a PYGEDU, donde la mejora es registrada y cuantificada.

Se observa que I $\mathrm{I}_{0}$ medio (ver Figura 8, identificado con la barra cuadriculada) es de $18 \%$, el cual puede ser fijado como umbral diferenciador de dos grupos, los que poseen un nivel de integralidad aceptable y los que caminan hacia ese umbral. En este contexto, Uruguay, Bolivia y Costa Rica ocupan los primeros lugares, por tanto, en función de este índice, se debería priorizar el envío de artículos PYGEDU a estos países. En cambio, Chile se encuentra levemente por debajo de la media, hecho que se transforma en un desafío para la producción científica en PYGEDU. 
doi: http://dx.doi.org/10.15359/ree.22-3.7

URL: http://www.una.ac.cr/educare

CORREO: educare@una.cr

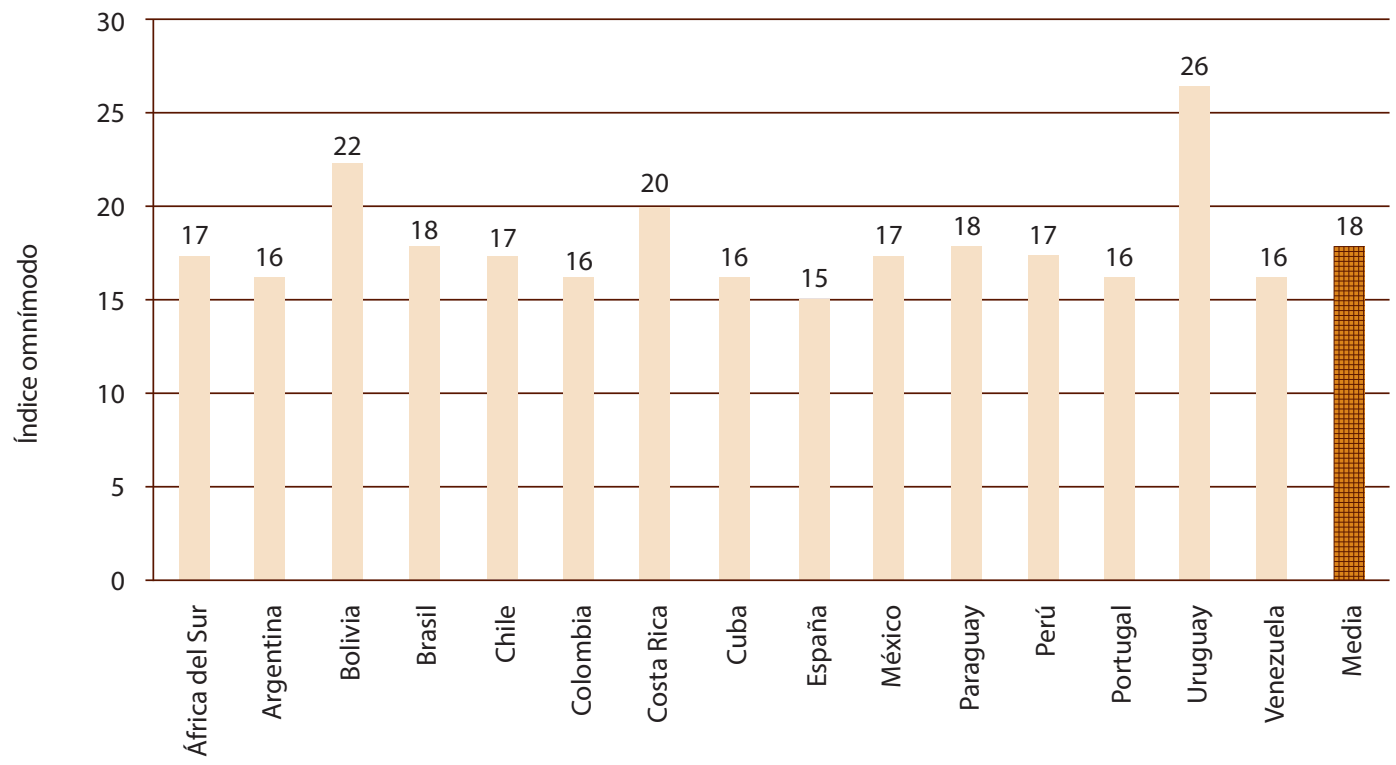

Países en base de indexación SciELO

Figura 8: Índice omnímodo longitudinal (2012-2015).

\section{Nota: Elaboración propia.}

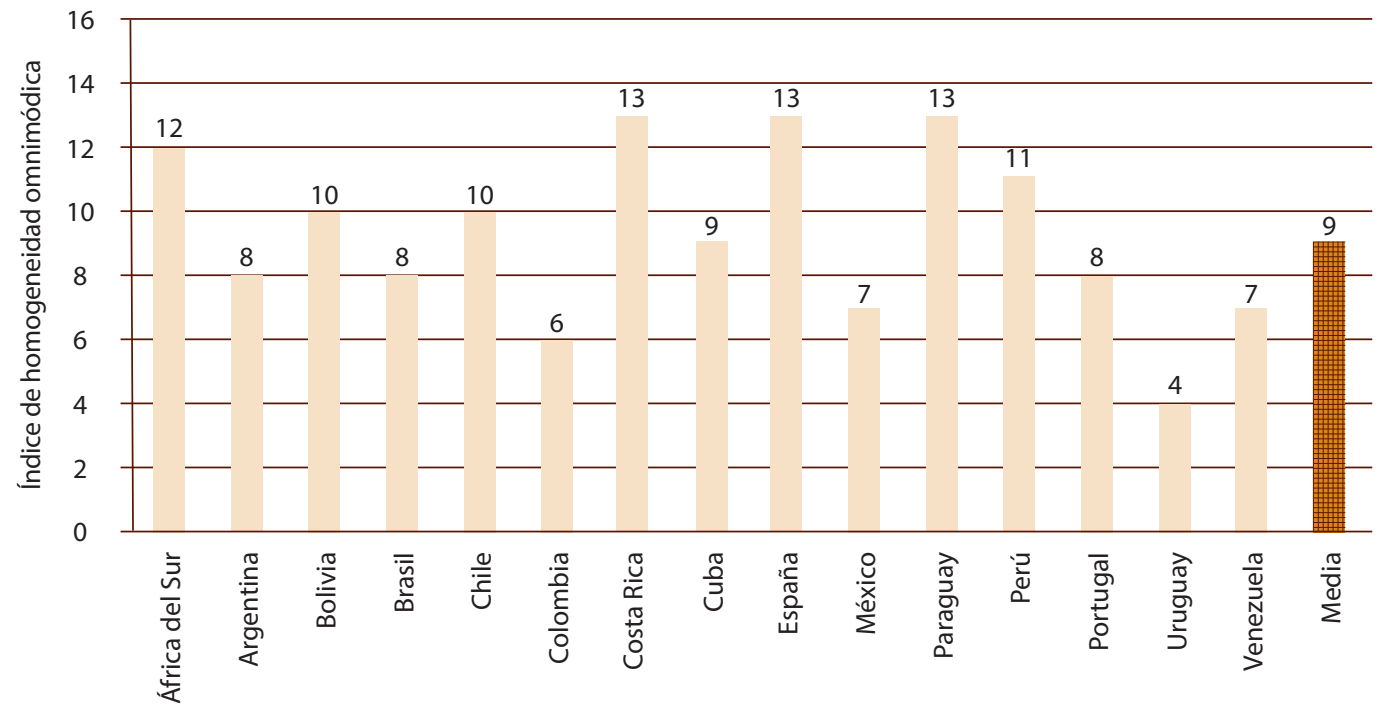

Países en base de indexación SciELO

Figura 9: Índice de homogeneidad longitudinal omnimódica (2012-2015).

Nota: Elaboración propia. 
En la Figura 9 se presenta un resumen de la estabilidad de $\mathrm{I}_{\mathrm{O}}$ en el tiempo, en donde es posible visualizar que Costa Rica, pese a presentar el mejor $\mathrm{I}_{\mathrm{O}^{\prime}}$ alcanza la máxima heterogeneidad, esto significa que no hay estabilidad en el índice, y que su comportamiento puede deberse a una situación atípica. Chile, esta vez supera a la media en forma leve. Así, mejorar I y disminuir su heterogeneidad pasa por estructurar criterios objetivos respecto de la cobertura en PYGEDU.

La Figura 10 presenta las trayectorias de los años 2012, 2013, 2014 y 2015, en relación con la dinámica de $\mathrm{I}_{\mathrm{o}}$. Se observa que Perú y Cuba son los únicos países que presentan un incremento en $\mathrm{I}_{\mathrm{O}}$. El año 2014 Chile se ve afectado fuertemente por una baja en $\mathrm{I}_{\mathrm{O}^{\prime}}$ aunque en el 2015 repunta, encontrándose en el primer lugar, es decir con el I o más alto.

La Figura 11 muestra cómo se comporta Chile en cuanto a los países con Io atípicos o escapados, visualizándose que Chile no sobrepasa o no se escapa a las situaciones extremas caracterizadas por España y Uruguay entre los años 2012 a 2014. No obstante, el año 2015 Chile se sobrepone a estos dos países. Se observa, además, que el comportamiento de $\mathrm{I}_{\mathrm{O}}$ es inverso entre Chile y Uruguay para el año 2014, por tanto, la situación atípica del año 2014 no es generalizable. La causa podría estar asociada a un aspecto o característica propia de Chile. Esta situación atípica abre una línea de investigación en torno a la causal de ese comportamiento.

\section{Jerarquización}

Finalmente se presentan en orden los resultados del $\mathrm{I}_{\mathrm{O}}$ por país y en coherencia a cada año, para, de tal manera, visualizar los países que se encuentran sobre el umbral caracterizado por la media. Así, para el año 2012 (ver Figura 12) los países que se posicionan positivamente sobre la media son Bolivia, Portugal, Cuba, Colombia, Brasil, Chile, México y Uruguay; Chile en el tercer lugar.

Para el año 2013 (ver Figura 13), los países que se posicionan positivamente sobre la media son Argentina, España, Paraguay, Chile, Costa Rica, Brasil, Uruguay y Bolivia; Chile en el cuarto lugar. Se visualiza que existen 4 países que se mantienen sobre el umbral tanto para el año 2012 como 2013, a saber: Chile, Brasil, Uruguay y Bolivia.

Para el año 2014 (ver Figura 14) los países que se posicionan positivamente sobre la media son Costa Rica, Paraguay, México, Uruguay, Bolivia, África del Sur y Brasil. Se observan 3 países que se mantienen sobre el umbral tanto para el año 2012, 2013 y 2014, a saber: Uruguay, Bolivia y Brasil. Chile se sitúa bajo el umbral.

Para el año 2015 (ver Figura 15) los países que se posicionan positivamente sobre la media son Brasil, Venezuela, Argentina, Uruguay, Colombia, Chile y Bolivia; se sitúa Chile sobre el umbral ocupando el segundo lugar en el ranking. Se observa que existen 3 países que se mantienen sobre el umbral tanto para el año 2012, 2013, 2014 y 2015: Uruguay, Bolivia y Brasil. 
doi: http://dx.doi.org/10.15359/ree.22-3.7

URL: http://www.una.ac.cr/educare

CORREO: educare@una.cr

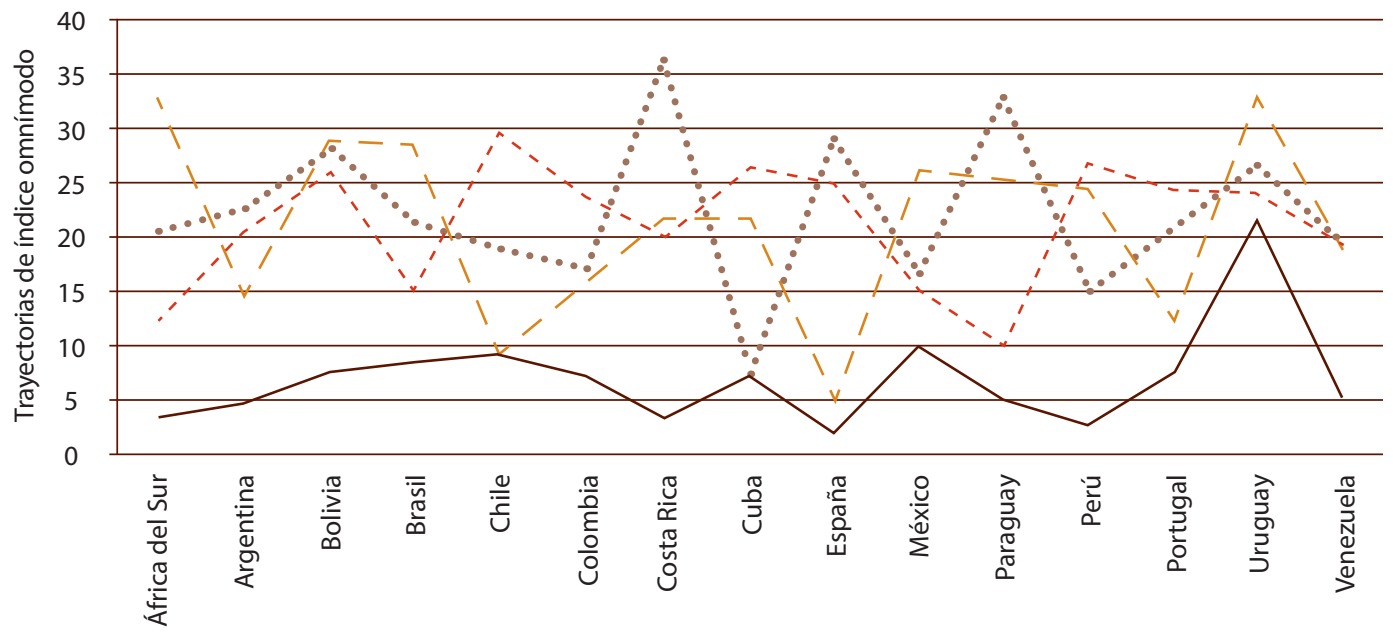

Países en base de indexación SciELO

$2012 \ldots \ldots .2013-2014 \quad \ldots-2015$

Figura 10: Dinámica longitudinal omnimódica (2012-2015).

Nota: Elaboración propia.

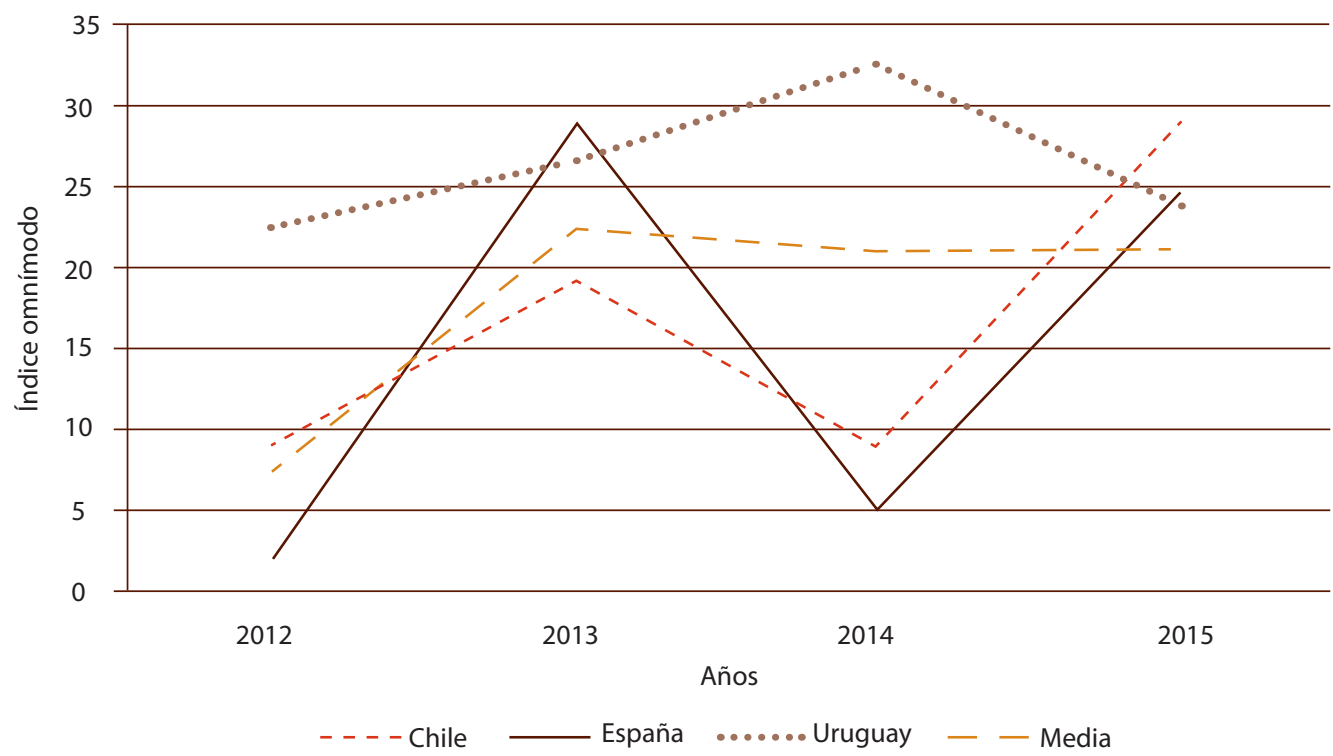

Figura 11: Valores extremos para $\mathrm{I}_{\mathrm{o}}$ (2012-2015).

Nota: Elaboración propia. 
doi: http://dx.doi.org/10.15359/ree.22-3.7

URL: http://www.una.ac.cr/educare

CORREO: educare@una.cr

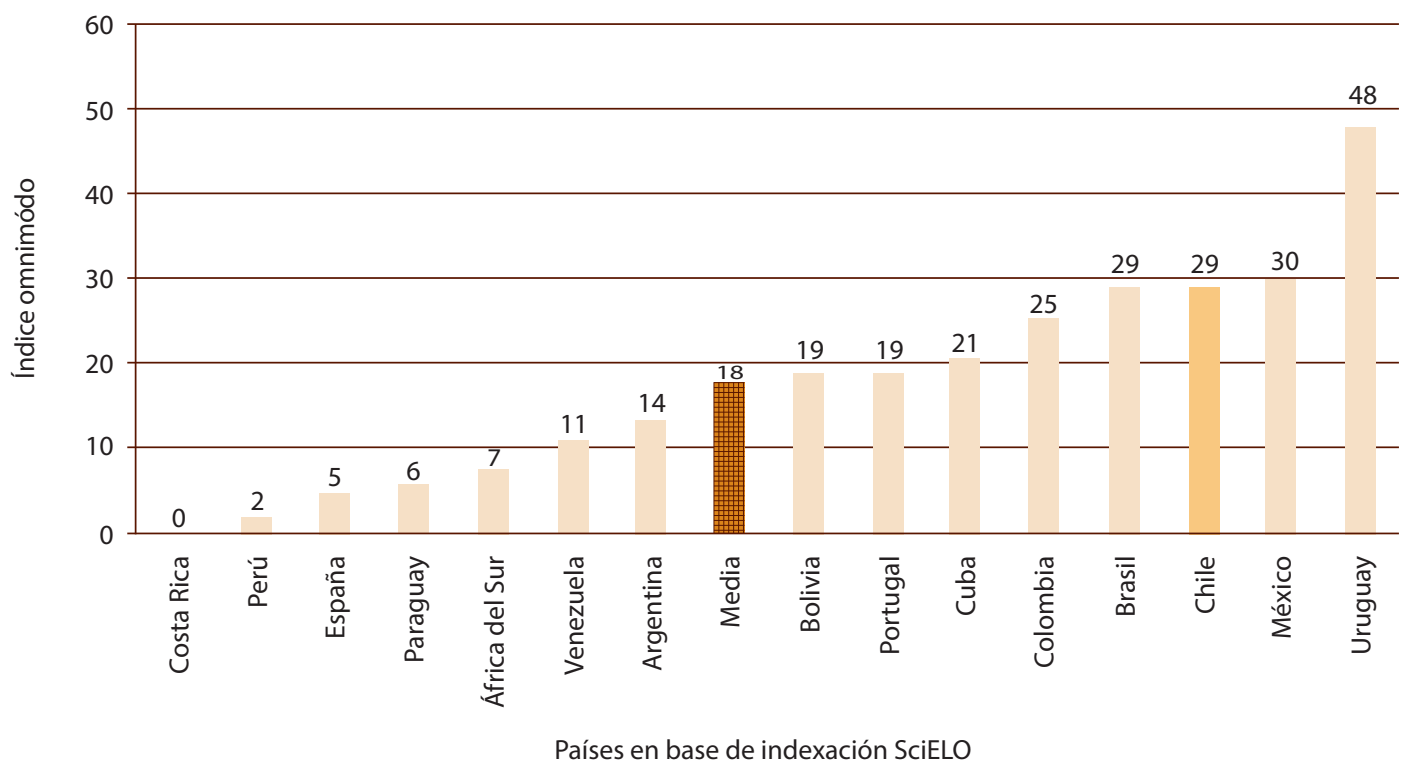

Figura 12: Jerarquización I en 2012.

Nota: Elaboración propia.

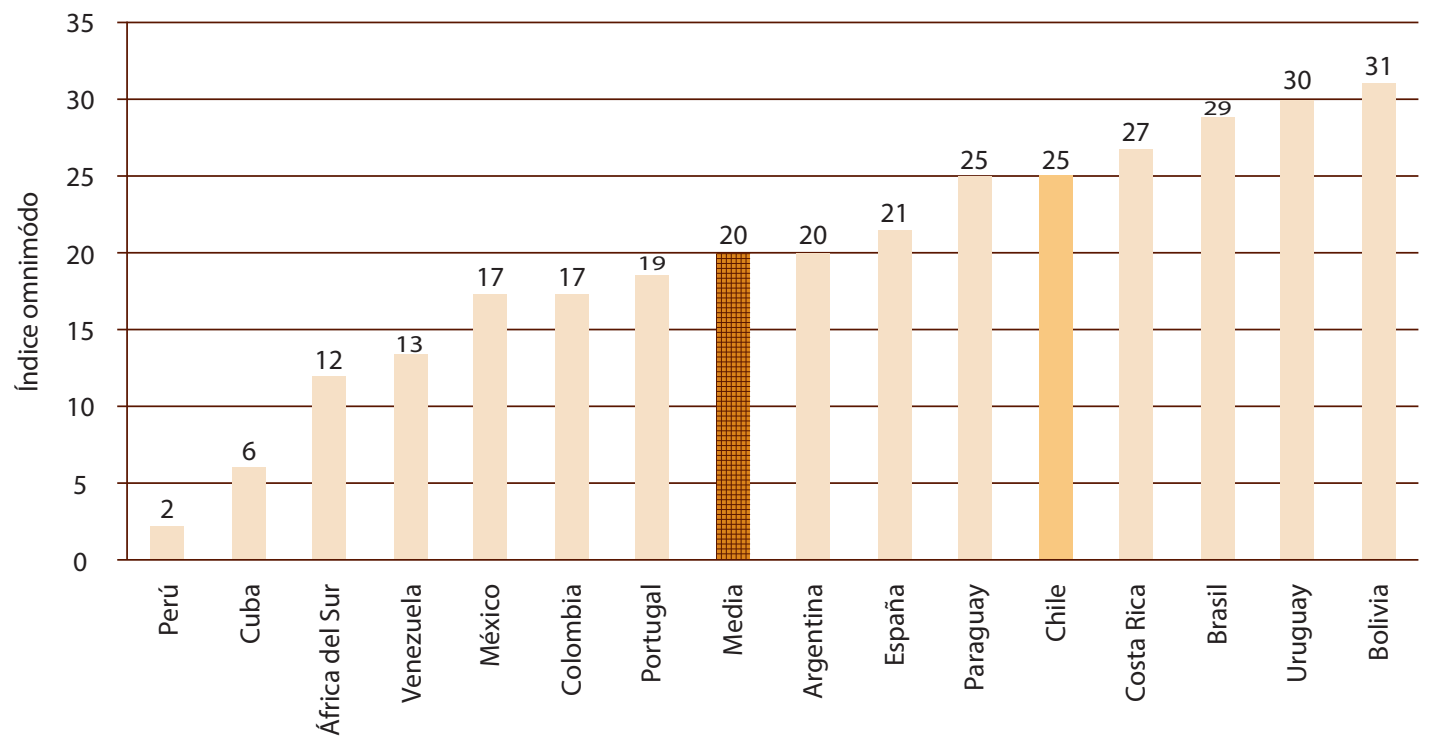

Países en base de indexación SciELO

Figura 13: Jerarquización I en 2013.

Nota: Elaboración propia. 
doi: http://dx.doi.org/10.15359/ree.22-3.7

URL: http://www.una.ac.cr/educare

CORREO: educare@una.cr

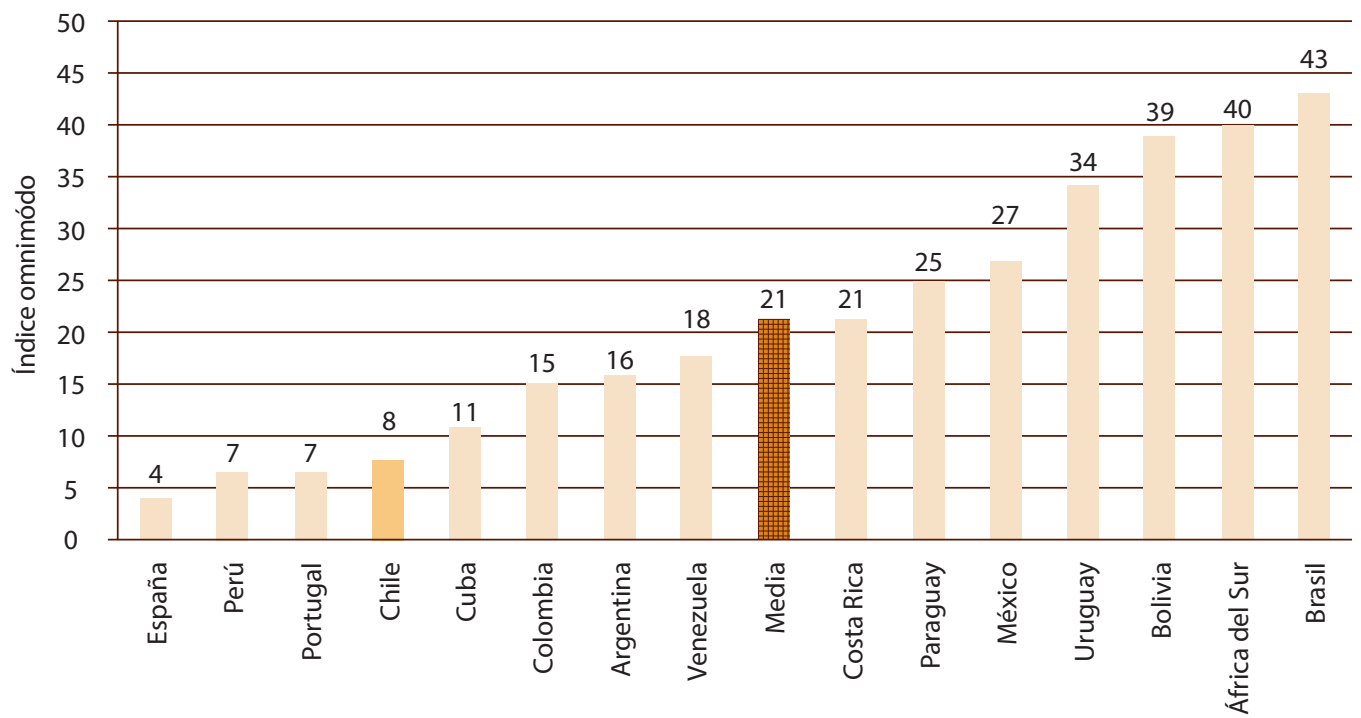

Países en base de indexación SciELO

Figura 14: Jerarquización I en 2014.

Nota: Elaboración propia.

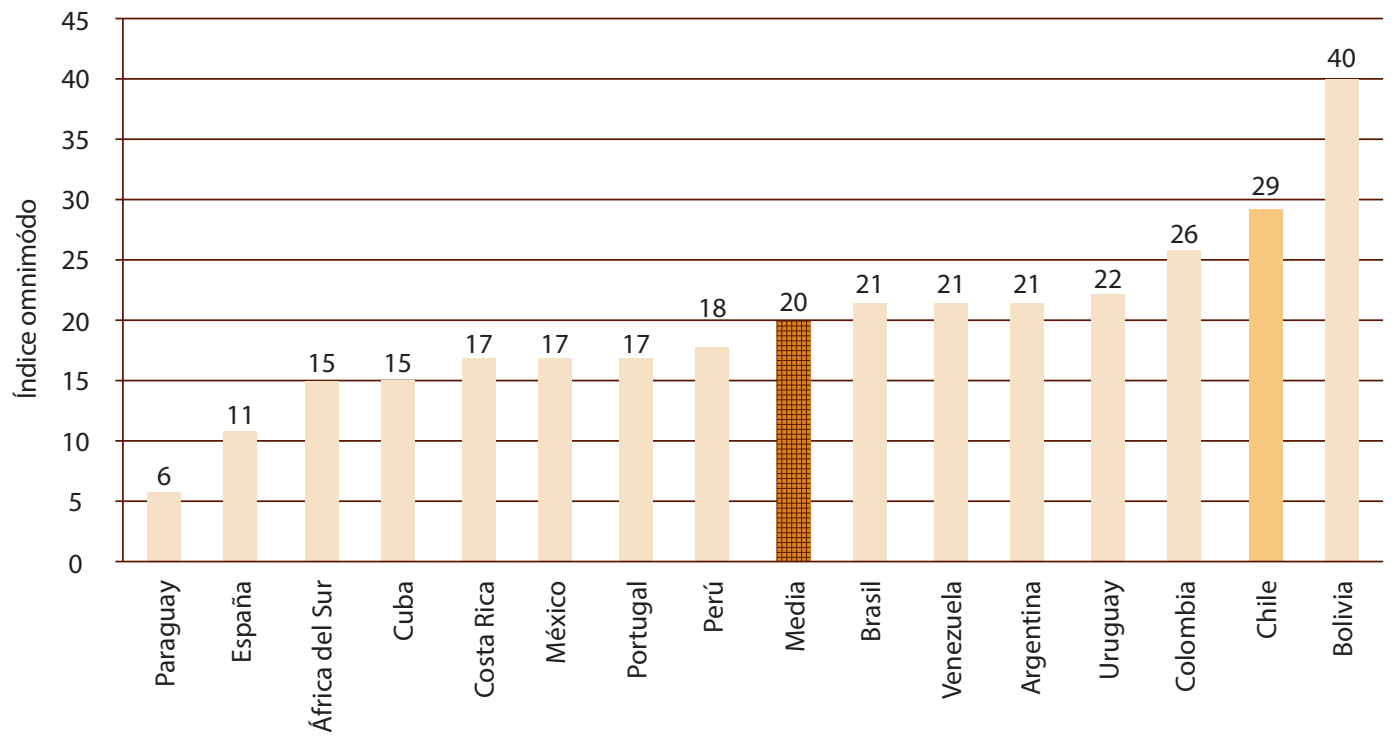

Países en base de indexación SciELO

Figura 15: Jerarquización I en 2015.

Nota: Elaboración propia. 
Por tanto, en un análisis año a año, se concluye que las mejores alternativas en cuanto a integralidad de las revistas de admisibilidad en educación para PYGEDU, son las pertenecientes a Uruguay, Bolivia y Brasil. Se reitera la exclusión de Chile, en este ranking total, debido al comportamiento atípico generado el año 2014.

\section{Conclusión}

La revisión longitudinal de publicaciones científicas en educación no es un tema nuevo en la cienciometría, por lo que es posible encontrar destacables trabajos en dicho ámbito, como los trabajos de Cardona-Román y Sánchez-Torres (2017); Corrales-Reyes et al. (2017); Osorio (2007); entre otros. Incluso es posible encontrar trabajos que superan la década de revisión (Fernández et al. 2003; Cabrera, 2016). Así y con la misma premisa longitudinal, el presente estudio analizó la producción científica entre los años 2012 y 2015 (ambos inclusive). La diferencia sustancial de la presente investigación, en relación con la extensión de la revisión y la propuesta de índice construido, encontró que la mayor parte de las de las investigaciones consideradas se concentran en la nacionalidad de los investigadores o investigadoras, o en su dependencia administrativa. En cambio, la presente investigación realizó una revisión temática de toda la fuente de indexación SCIELO, sin importar el origen de los autores y las autoras o su dependencia administrativa.

Por lo demás, en la mayor parte de las investigaciones presentadas, los datos o resultados expuestos respecto del área de políticas y gestión educativa fueron un resultado periférico, con excepción del trabajo de Villalobos et al. (2016), ya que no constituía el punto central de las investigaciones o simplemente era parte de un conjunto de temáticas más amplia. No obstante, esta investigación se centró exclusivamente en la materia de políticas y gestión educativa, por lo que es posible afirmar que es uno de los primeros estudios de esta naturaleza en el área específica, aun cuando amplía resultados precedentes. Tal es así que esta investigación confirma los resultados encontrados por Osorio (2007), quien determinó que, dentro de su contexto muestral, el $28,23 \%$ de los artículos se refirió a temáticas de política y gestión en el ámbito educativo, algo muy cercano al $25 \%$ aquí encontrado.

Asimismo, es importante destacar que el análisis de las revisiones presentadas es fundamentalmente descriptivo, centrado fuertemente en parámetros de citación. En cambio, la presente propuesta, no solo describe los hallazgos, sino que avanza un paso más proponiendo un índice omnímodo que oriente a los grupos de investigación en políticas y gestión educativa, ya sea para buscar información o para publicar sus trabajos. Al respecto, el índice omnímodo identificó los países con menor riesgo y estabilidad longitudinal en relación con la producción científica en política y gestión educativa: Bolivia, Brasil y Uruguay. Asimismo, identificó los países de mayor riesgo e inestabilidad en relación con la producción científica en política y gestión educativa: Perú y África del Sur. 
doi: http://dx.doi.org/10.15359/ree.22-3.7

URL: http://www.una.ac.cr/educare

CORREO: educare@una.cr

De esta manera y en relación con la hipótesis planteada que señala que la producción científica en PYGEDU, según el índice omnímodo, en los 15 países de la base de indexación SCIELO es homogénea y estable en el tiempo en términos relativos, conviene rechazar dicha afirmación, pues según lo revisado se dista de estandarizaciones, políticas y criterios de regulación de la producción científica en política y gestión educativa. Esto se traduce en que existe baja e inestable producción científica en esta área y que, consecuentemente, existe poco respaldo científico para las políticas y acciones educativas llevadas a cabo en los países representados en la base de indexación SCIELO.

Por su parte, y como toda obra humana, es posible desarrollar este estudio. Tal vez sería conveniente, en futuras indagaciones, realizar una selección de artículos exclusivamente con base en las palabras claves indicadas, para no utilizar el juicio de personal experto para categorizarlos, tal como se utilizó en este trabajo. Sin embargo, creemos que esto no es una desventaja del trabajo, más bien es una elección metodológica válida. De la misma forma, sería posible revisar bases de indexación angloparlantes, con el propósito de observar si la producción de conocimiento en PYGEDU de quienes escriben en Latinoamérica (representantes de la mayoría de los países de la base SCIELO), está comunicada en dicho idioma.

Finalmente, la presente investigación y sus resultados abren espacios para futuros estudios, uno de los cuales pudiera estar centrado en determinar las causales del comportamiento atípico en la producción científica en política y gestión educativa en Chile durante el año 2014. Por ejemplo, se ha planteado como presunción el efecto de los ciclos presidenciales, cuyo cambio se sucede justamente cada cuatro años (en 2014 asume un nuevo gobierno), lo que puede ser un elemento de contexto que enfoca la atención investigativa en temáticas más asociadas a la ciencia política que a la educación y, en este caso, ha provocado una caída en la producción de conocimiento en política y gestión educativa. Esto nuevamente trae a colación los efectos de la política en la producción de conocimientos detectados por Villalobos et al. (2016), y los efectos performativos que dicha política tiene tanto en términos normativos, estructurales como cotidianos (Acuña et al. 2014; Ball, 2014; Bourdieu, 1997).

El desafío queda abierto.

\section{Referencias}

Acuña, F., Assaél, J., Contreras, P. y Peralta, B. (2014). La traducción de los discursos de la política educativa en la cotidianeidad de dos escuelas municipales chilenas: La metáfora médica como vía de análisis. Psicoperspectivas, 13(1), 46-55. doi: https://doi.org/10.5027/ psicoperspectivas-Vol13-Issue1-fulltext-363

Arencibia, R., y De Moya, F. (2008). La evaluación de la investigación científica: Una aproximación teórica desde la cienciometría. ACIMED, 17(4), 1-27. Recuperado de http://scielo.sld.cu/ scielo.php?script=sci arttext\&pid=S1024-94352008000400004\&lng=es\&tIng=es 
Ball, S. J. (2014). Globalización, mercantilización y privatización: Tendencias internacionales en educación y política educativa. Archivos Analíticos de Políticas Educativas, 22(41), 1-17. doi: https://doi.org/10.14507/epaa.v22n41.2014

Bourdieu, P. (1997): Razones prácticas. Sobre la teoría de la acción. Barcelona: Anagrama.

Cabrera, L. (2016). Revisión sistemática de la producción española sobre rendimiento académico entre 1980 y 2011. Revista Complutense de Educación, 27(1), 119-139. doi: https://doi. org/10.5209/rev RCED.2016.v27.n1.45293

Cardona-Román, D. M., y Sánchez-Torres, J. M. (2017). Análisis cienciométrico de la producción científica acerca de la investigación sobre la evaluación de la implementación del e-learning en el periodo 2000-2015. Educación, 26(51), 7-34. doi: https://doi.org/10.18800/ educacion.201702.001

Casassus, J. (2002). Problemas de la gestión educativa en América Latina: La tensión entre los paradigmas de tipo A y el tipo B. Em Aberto, Brasília, 19(75), 49-69. Recuperado de http:// emaberto.inep.gov.br/index.php/emaberto/article/view/2167/2136

Corrales-Reyes, I. E., Fornaris-Cedeño, Y., y Reyes-Pérez, J. J. (2017). Análisis bibliométrico de la revista investigación en educación médica. Período 2012-2016. Investigación en Educación Médica, en prensa. doi: https://doi.org/10.1016/j.riem.2017.02.003

Cruz-Ramírez, M., Escalona-Reyes, M., Cabrera-García, S. y Martínez-Cepena, M. C. (2014). Análisis cienciométrico de las publicaciones educacionales cubanas en la Wos y Scopus (2003-2012). Revista Española de Documentación Científica, 37(3), 1-15. doi: https://doi. org/10.3989/redc.2014.3.1119

Díaz, A. (2003). Una discreta diferenciación entre la política y lo político y su incidencia sobre la educación en cuanto a la socialización política. Reflexión política, 5(9), 48-58. Recuperado de http://www.redalyc.org/pdf/110/11000904.pdf

Diem, A. y Wolter, S. C. (2013). The use of bibliometrics to measure research performance in education sciences. Research in Higher Education, 54(1), 86-114. doi: https://doi. org/10.1007/s11162-012-9264-5

Fernández, A. y Bueno, A. (1998). Síntesis de estudios bibliométricos españoles en educación. Una dimensión evaluativa. Revista española de documentación científica, 21(3), 269-285. doi: https://doi.org/10.3989/redc.1998.v21.i3.356

Fernández, A., Torralbo, M., Rico, L., Gutiérrez, P. y Maz, A. (2003). Análisis cienciométrico de las tesis doctorales españolas en Educación Matemática (1976-1998). Revista española de documentación científica, 26(2), 162-176. doi: https://doi.org/10.3989/redc.2003.v26.i2.135 
doi: http://dx.doi.org/10.15359/ree.22-3.7

URL: http://www.una.ac.cr/educare

CORREO: educare@una.cr

López, W. (2017). ¿Puede la cienciometría contribuir a la evaluación de la producción intelectual? Universitas Psychologica, 16(4), 1-3. Recuperado de http://www.redalyc.org/articulo. oa?id=64753569001

Mouffe, C. (1999). El retorno de lo político. Comunidad, ciudadanía, pluralismo, democracia radical. Barcelona: Paidós.

Ortiz, E. A. (2015). La evaluación del impacto científico en las investigaciones educativas a través de un estudio de caso. Revista electrónica de investigación educativa, 17(2), 89-100. Recuperado de http://www.scielo.org.mx/scielo.php?script=sci arttext\&pid $=$ S1607-40412015000200007

Osorio, R. (2007). La investigación educativa en México vinculada con la práctica. La producción reportada en la RMIE. Revista Mexicana de Investigación Educativa (RMIE), 12(33), 763-781. Recuperado de http://www.comie.org.mx/documentos/rmie/v12/n033/pdf/N33N.pdf

Rico, A. D. (2016). La gestión educativa: Hacia la optimización de la formación docente en la educación superioren Colombia.:OФIA-Sophia, 12(1),55-70.doi:https://doi.org/10.18634/ sophiaj.12v.11.445

Villalobos, C., Band, A., Torres, M. y González, S. (2016). Lógicas y modos de producción de conocimiento en política educativa: Análisis de la investigación producida en Chile (2000-2011). Revista iberoamericana de ciencia tecnología y sociedad, 11(33), 9-32. Recuperado de http://www.scielo.org.ar/scielo.php?script=sci arttext\&pid=S1850$00132016000300002 \& \operatorname{lng}=$ es\&tlng=es 